\title{
FLUTUAÇÃO POPULACIONAL DE EUSPILOTUS RUBRICULUS (MARSEUL) (COLEOPTERA, HISTERIDAE), EM GRANJA AVÍCOLA, EM PELOTAS, RS
}

\section{D.M. Pinto; P.B. Ribeiro}

Universidade Federal de Pelotas, Instituto de Biologia, Departamento de Microbiologia e Parasitologia, CP 354, CEP 96010-900, Pelotas, RS, Brasil. E-mail: dimoscarelli@yahoo.com.br

\section{RESUMO}

\begin{abstract}
O trabalho relata a flutuação populacional de Euspilotus rubriculus (Coleoptera, Histeridae) coletados através de armadilhas do tipo Arend ou "tubo" e do tipo "sanduíche". O experimento foi realizado no período de abril de 2002 a março de 2003, em aviário do Conjunto Agrotécnico Visconde da Graça (CAVG), localizado em Pelotas, Rio Grande do Sul, Brasil. Nesse período foram capturados 219 exemplares de E. rubriculus, sendo o período de maior ocorrência no mês de fevereiro (72), quando a temperatura média mensal foi de $24,7^{\circ} \mathrm{C}$ e o menor índice de coleta ocorreu nos meses de maio e setembro (1). E. rubriculus apresentou uma variação da densidade populacional ao longo do ano, sendo as maiores médias de captura obtidas nos meses com maiores temperaturas médias, demonstrando a potencial importância desta espécie em aviários.
\end{abstract}

PALAVRAS-CHAVE: Predador, controle biológico, aviário, monitoramento.

\section{ABSTRACT}

POPULATIONFLUCTUATIONSOFEUSPILOTUSRUBRICULUS (COLEOPTERA,HISTERIDAE), A POULTRY FARM IN PELOTAS, RS, BRAZIL. This paper reports the population fluctuation of Euspilotus rubriculus (Coleoptera, Histeridae) collected from Arend's traps ("tube" type) and "sandwich" type, from April 2002 to March 2003, at the aviary Conjunto Agrotécnico Visconde da Graça (CAVG), located in Pelotas, Rio Grande do Sul, Brazil. In this period 219 specimens of E. rubriculus were captured, the period of largest occurrence being the month of February (72), when the average monthly temperature was $24.7^{\circ} \mathrm{C}$, while the smallest collection index occurred in the months of May and September (1). E. rubriculus presented a variation of population density along the year, with the largest average captures obtained in the months with higher average temperatures, demonstrating the potential importance of this species in aviaries.

KEY WORDS: Predator, biological control, aviary, monitoring.

A indústria avícola está em contínua expansão no Brasil, conquistando espaços cada vez maiores no mercado externo. Porém, o confinamento das aves, visando ao aumento da produção, propiciou a ocorrência de artrópodes no agroecossistema dos aviários, trazendo problemas de difícil solução (Chernaki; Almeida, 2001).

Desde que o homem começou a confinar animais, o controle dos artrópodes tem sido um constante desafio, além disso, o uso indiscriminado de inseticidas químicos geralmente utilizados nos programas de controle destas pragas polui o ambiente, contamina a carne, os ovos e o leite, e agrava ainda mais o problema nas criações (LopEs et al., 2006).

As fezes das aves que se acumulam nos aviários servem de meio para o desenvolvimento de várias espécies de artrópodes, como alguns dípteros muscóideos sinantrópicos que são vetores de patógenos para o homem e os animais, bem como seus inimigos naturais como os coleópteros da família Histeridae (LOPEs et al., 2006).

Os Histeridae apresentam hábitos predatórios, tanto na fase larval, quanto na adulta. Buscam seus alimentos, principalmente, em ambientes em decomposição, onde, ao encontrarem larvas de primeiro e segundo ínstares de dípteros sinantrópicos, atuam como predadores ou como agentes de "manejo físico". Desta forma, ocorrem em fezes animais, auxiliando no controle de moscas de importância médica e veterinária que aí se desenvolvem (CLARK, 1895; PeCK; Anderson, 1969; Rodrigues; MARChini, 1998).

Oestudo das espécies que ocorrem nos ambientes de confinamento de aves assume importância não só ecológica, pois a associação destas espécies à veiculação dos mais diversos organismos patogênicos se reveste de interesse sanitário (MASCARINI, 1995).

Dentre as espécies de Euspilotus (Coleoptera: Histeridae), assinaladas para o Brasil como preda- 
doras de mosca, estão Euspilotus arrogans e Euspilotus modestus e duas espécies não identificadas (MARICONI et al., 1999).

Euspilotus rubriculus teve sua ocorrência assinalada pela primeira vez em aviário para o Brasil, por BicHoet al. (2005). Esta espécie, provavelmente, possui hábitos predatórios, assim como E. modestus, estudada por GianizelLA (2000), cujos adultos consomem ao redor de 26 ovos de Chrysomya putoria por dia.

Com base no provável potencial de E. rubriculus como predador de ovos de moscas em aviários, realizou-se este trabalho para verificar sua ocorrência e flutuação populacional, visando conhecer seu comportamento ao longo do ano, bem como seu potencial uso em futuros programas de controle biológico.

O estudo foi realizado em um aviário experimental, durante o período de abril de2002 a março de 2003. A coleta dos insetos foi realizada por meio de dois métodos: (1) armadilha do tipo "tubo" ou de Arends (SAFRIT; Axtell, 1984), que consiste em um tubo de polivinilcloreto (PVC) $(3,8 \mathrm{~cm}$ de diâmetro $\times 23 \mathrm{~cm}$ de comprimento), contendo em seu interior papel corrugado, colocado de forma que as ondulações fiquem dispostas em sentido longitudinal ao tubo e (2) armadilha do tipo "sanduíche" (SAFRIT; AxTELL, 1984), constituída por caixas de madeira $(20 \mathrm{~cm}$ de comprimento $\times 15 \mathrm{~cm}$ de largura $\times 8 \mathrm{~cm}$ de altura), com tampa e duas aberturas de $1 \mathrm{~cm}$ no sentido longitudinal, junto à base da caixa, para facilitar a

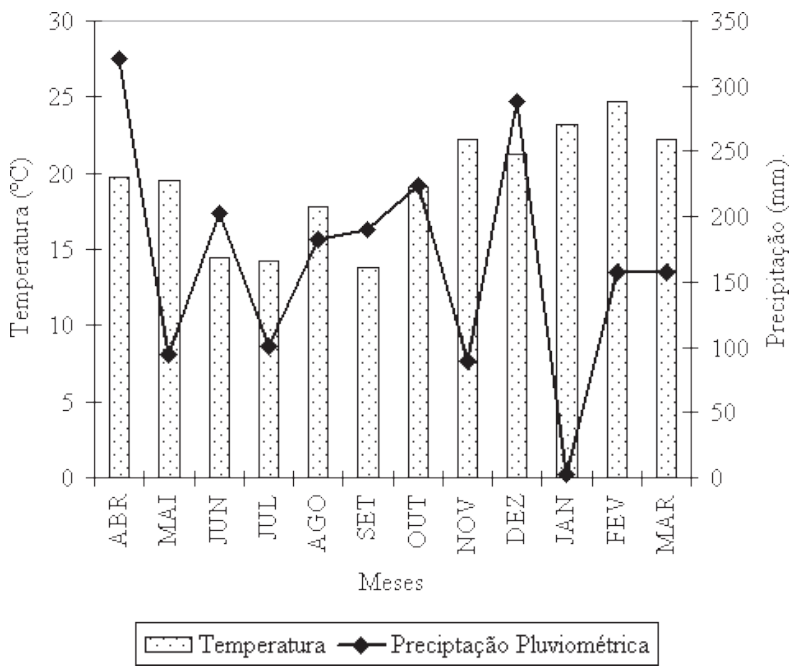

Fig. 1 - Temperatura Média Mensal e Precipitação Pluviométrica, no período de abril de 2002 a março de 2003, em Pelotas, RS. entrada dos insetos, e no interior, papel corrugado, preenchendo totalmente a armadilha.

Foram instaladas 16 armadilhas, em grupos de quatro, em quatro locais diferentes do galpão. Cada grupo composto por duas armadilhas do tipo "sanduíche" e duas armadilhas do tipo "tubo". As armadilhas foram colocadas, sobre a cama (maravalha), dispostas lado a lado equidistantes $30 \mathrm{~cm}$ umas das outras.

Foram feitas coletas semanais e o conteúdo de cada armadilha era colocado em um recipiente plástico com tampa, devidamente identificado, com o auxílio de um funil de alumínio. Nas avaliações, o papel do interior das armadilhas era substituído por um novo e os insetos capturados eram levados para o laboratório onde se realizava a triagem, identificação e contagem. Após esse procedimento, os insetos foram armazenados em potes de vidro devidamenteidentificados, contendoálcool $70 \%$.Os dados climatológicos foram fornecidos pela Estação Climatológica do Conjunto Agrotécnico Visconde da Graça, próximo ao local onde se realizou o trabalho.

Os resultados foram submetidos à análise de regressão polinomial, utilizando-se o programa estatístico SANEST (ZoNTA; MACHADO, 1984).

Durante o período experimental foram capturados 219 espécimens de Euspilotus rubriculus, tendo ocorrido o acme populacional no mês de fevereiro (72) onde a temperatura média mensal foi de $24,7^{\circ} \mathrm{C}$ e o menor índice de coleta nos meses de maio e setembro (1). Nos meses de abril, junho, julho e agosto não houve captura dessa espécie (Tabela 1).

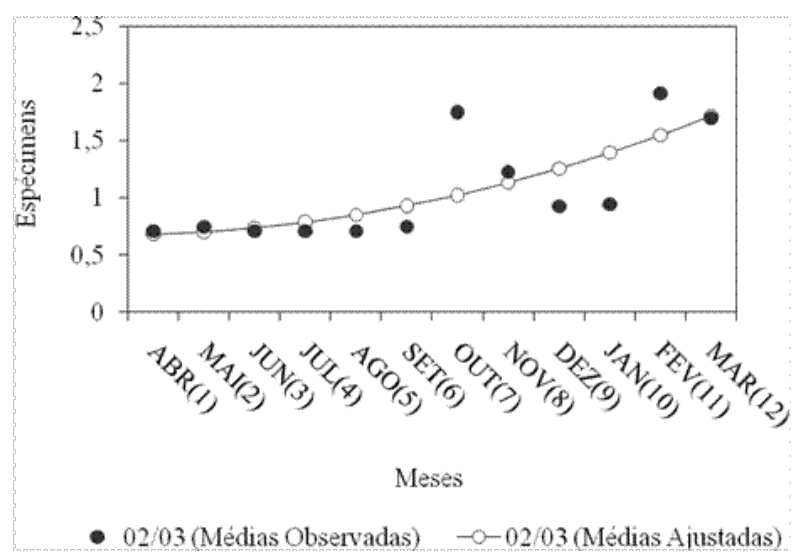

Fig. 2 - Flutuação populacional de Euspilotus rubriculus, em granja avícola, no período de abril de 2002 a março de 2003, em Pelotas, RS.

Tabela 1 - Ocorrência mensal de Euspilotus rubriculus, capturados em galpão de aves poedeiras, no período de abril de 2002 a março de 2003, em Pelotas, RS.

\begin{tabular}{lccccccccccccc}
\hline Espécie & \multicolumn{11}{c}{ Meses $(2002 / 2003)$} \\
\cline { 2 - 12 } & Abr. & Mai. & Jun. & Jul. & Ago. & Set. & Out. & Nov. & Dez. & Jan. & Fev. & Mar. & Total \\
Euspilotus rubri & - & 1 & - & - & - & 1 & 66 & 22 & 7 & 8 & 72 & 42 & 219 \\
\hline
\end{tabular}


Na Figura 1 pode-se observar que a temperatura média mensal variou de $13,8^{\circ} \mathrm{C}$ (setembro) a $24,7^{\circ} \mathrm{C}$ (fevereiro) e a precipitação pluviométrica acumulada mensal oscilou de 2,63 $\mathrm{mm}$ (janeiro) a $321,57 \mathrm{~mm}$ (abril).

A flutuação populacional de E. rubriculus capturada em galpão de poedeiras pode ser observada na Figura 2. O modelo ajustado foi o quadrático, com significância a $0,001 \%$, com coeficiente de determinação de $92,74 \%$. O modelo ajustado foi: $y_{i}=1,2090$ $-0,3644 x_{i}+0,0524 x_{i}^{2}$, onde $i=1,2, \ldots, 11,12$ (ordem dos meses do ano).

Segundo Bicho et al. (2005), que assinalaram pela primeira vez a ocorrência desta espécie no Brasil, $E$. rubriculus ocorreu durante os doze meses de coleta, apresentando acme populacional no mês de abril (41) e a menor ocorrência nos meses de outubro e novembro (01), esta diferença pode estar relacionada com os métodos utilizados.

Segundo Legner; Olton (1970), algumas espécies de Euspilotus ocorrem em diversos excrementos, como E. liticolus (galinha e equinos, Sul da Califórnia e bovinos, Sul do México e Sul da Califórnia).

FERNANDEs et al. (1995) e GIANIZELLA; PRADO (1998) relataram a presença de Euspilotus sp., em excrementos de galinhas em granjas em Uberlândia, MG, e São Paulo, SP.

Mais recentemente, Lopes et al. (2006), estudando a abundância e sazonalidade de histerídeos (Coleoptera) associados ao esterco de granja aviária da região Nordeste do Estado de São Paulo, Brasil, coletaram 89.044 Histeridae, pertencentes às espécies: Euspilostus modestus (Erichson, 1834), Euspilostus (Hesperosaprinus) spp., Carcinops troglodytes (Paykull, 1811)e Hololeptaquadridentata (Fabricius, 1801). Sendo que, quando somados os dois métodos de coleta, $E$. modestus e C. troglodytes corresponderam a $98,53 \%$ de todos histerídeos coletados, evidenciando um alto grau de adaptação a esse substrato artificial produzido em criação industrial de aves poedeiras.

E. rubriculus ocorreu durante oito meses do ano, variando a densidade populacional ao longo dele, sendo as maiores médias de captura obtidas nos meses com maiores temperaturas médias.

A ocorrência deste coleóptero em aviários demonstra a importância dessa espécie na artropodofauna avícola, devido ao seu possível potencial como predador e evidencia a necessidade de estudos mais aprofundados.

\section{REFERÊNCIAS}

BICHO, C.L.; ALMEIDA, L.M.; RIBEIRO, P.B.; SILVEIRA JUNIOR, P. Flutuação populacional circanual de coleópteros em granja avícola em Pelotas, RS, Brasil. Iheringia. Série Zoologia, v.95, p.205-212, 2005.
CHERNAKI, A.M.; ALMEIDA, L.M. Exigências térmicas, período de desenvolvimento e sobrevivência de imaturos de Alphitobius diaperinus (Panzer) (Coleoptera: Tenebrionidae). Neotropical Entomology, v.30, n.3, p.365368, 2001.

CLARK, C.U. On the certain dung and carrion beetles. Journal of the New York Entomological Society, v.3, p. 61, 1895.

FERNANDES, M.A.; SANTOS, M.A.S.; LOMÔNACO, C. Ocorrência de artrópodes no esterco acumulado em uma granja de galinhas poedeiras. Anais da Sociedade Entomológica do Brasil, v.24, n.3, p.649-654, 1995.

GIANIZELLA, S.L. Observação em laboratório de ciclos biológicos e hábitos de duas espécies de Histeridae (Coleoptera): Euspilotus modestus (Erichson) e Carcinops troglodites Paykull e sua possível utilização no controle biológico de dípteros sinantrópicos em granja de aves poedeiras. 2000. 136p. Tese (Doutorado) - Universidade Estadual de Campinas, Campinas, 2000.

GIANIZELLA, S.L.; PRADO, A.P. Levantamento e sazonalidade de coleópteros (Histeridae) em criação de aves poedeiras. Anais da Sociedade Entomológica do Brasil, v.27, n.4, p.551-555, 1998.

LEGNER, E.F.; OLTON, G.S. Worlwide survey and comparison of adult predator and scavenger insect populations associated with domestic animal manure where livestock is artificially congregates. Hilgirdia, v.40, n.9, p.225-266, 1970.

LOPES, W.D.Z.; LOPES, W.C.Z.; COSTA, F.H.; BALEIRO, J.C.C.; PRADO, A.P. Abundância e sazonalidade de histerídeos (Coleoptera) associados ao esterco de granja aviária da Região Nordeste do Estado de São Paulo, Brasil. Revista Brasileira de Entomologia, v.50, n.4, p.492-497, 2006.

MARICONI, F.A.M.; GUIMARÃES, J.H.G.; BERTI FILHO, E. A mosca doméstica e algumas outras moscas nocivas. Piracicaba: Fundação de Estudos Agrários Luiz de Queiroz., 1999. 135p.

MASCARINI, L.M. Aspectos biológicos de Muscina stabulans (Fallén, 1817) em condições de laboratório. 1995. 68f. Dissertação (Mestrado em Entomologia). Universidade Estadual de Campinas, Campinas, SP. 1995.

PECK, J.H.; ANDERSON, J.R. Arthropod predators of immature Diptera developing in poultry droppings in Northern California. Part I. Determination, seasonal abundance and natural cohabitation with prey. Journal of Medical Entomology, v.6, p.163-167, 1969.

RODRIGUES, S.R; MARCHINI, L.C. Espécies de Histeridae coletadas em Piracicaba/SP. Scientia Agricola, v.55, p.1-7, 1998. 
SAFRIT, R.D.; AXTELL R.C. Evaluations of sampling methods for darkling beetles (Alphitobius diaperinus) in the litter of turkey and broiler houses. Poultry Science, v.63, n.12, p.2368-2375, 1984.

ZONTA, E.P.; MACHADO, A.A. SANEST - Sistema de Análise Estatística para Microcomputadores. Registrado na
Secretaria Especial de Informática sob nº 066060 categoria A. Pelotas, RS: Universidade Federal de Pelotas, 1984

Recebido em 9/8/10

Aceito em 24/10/11 